\title{
The contemporary interpretation of Laozi's thoughts on War and Peace NIU Dian-qing
}

(Ningbo City College of Vocational Technology, Ningbo 315100, China)

Key words: Lao Tzu; war concept; world peace; strategy and tactics; waterway;

Abstract: The Five Thousand Words of the Tao Te Ching contain Laozi's concept of war and peace in the world. He believes that as long as the country "does not take the military as its strength to master the world", war can be avoided. In addition, Laozi believes that seeking peace in the world is the way for countries to coexist harmoniously. He also holds the point of view that the tactics is the key for winning the victory, and "doing nothing" is important, which means that letting nature to take its course is the key step toward dominating the world. Defense is more important than attack, and this is how his philosophical thought of "inaction" be applied in military.

\section{老子战争与和平思想的当代阐释 \\ 牛殿庆 \\ 1宁波城市职业技术学院, 鄞州, 宁波, 浙江, 中国 ${ }^{*}$}

关键词: 老子; 战争; 和平; 战略战术; 水道; 水德

摘要：《道德经》五千言包含了老子的战争观与天下和平的理念, 只要国与国之间都能 “不 以兵强天下” 就可以避免战争, 国际之间修 “水道” 与 “水德” 行处下之道谦下之德, 谋求 天下和平, 国与国就能和谐共存。老子认为应采取出奇制胜的战术赢得战争, 目的是 “以无 事取天下” ; 应以守为主, 原则是 “不敢为天下先” , 这是老子 “无为” 哲学思想在军事上 的应用。

\section{1.引言}

从战争哲学的视角研究老子, 就可以在《道德经》五千言中分析出老子的战争与和平的 辩证思想。老子的政治思想是统治者实行“无为而治”来达到天下和平，以进攻掠夺为特性的 “有为”战争是与老子思想对立的。习近平总书记在中国国际友好大会暨中国人民对外友好协 会成立 60 周年纪念活动上的讲话中指出: “中华文化崇尚和谐, 中国“和”文化源远流长, 蕴涵 着天人合一的宇宙观、协和万邦的国际观、和而不同的社会观、人心和善的道德观。”这是 对老子战争与和平思想的深刻理解和活学活用。

\section{2. 战争与和平: “有为”与“无为”的哲学}

老子对待战争的态度是 “以无事取天下”，“不敢为天下先”，每个国家首先要道德自律， 然后, 通过 “守” 以奇用兵对待那些狂妄的“有为”战争, 最后赢得战争, 这是老子处世哲学中 的退守、谦下原则的战争与和平思想的具体表现，是老子“无为”哲学思想在军事上的应用。 就是张召忠说的: “我们不主动挑起战争, 但我们必须要做好战争的准备。”2老子的“哀兵必 
胜，骄兵必败”的军事思想，是对“有为”呈勇斗狠的霸权主义者的警示。老子还认为科技发明 的“利器”, 是国家混乱民生调政的根源。

\section{1“无为”不是不抵抗}

老子说: “夫惟兵者不祥之器”, 战争不是好事, 如果非要发动战争, 也是被迫“不得已 而用之”，国家之间不要军备竞赛好勇逞强，即“不以兵强天下”就可以和平共处。

首先，老子阐述了“无为”的军事哲学，即后发制人，以守为攻，以退为进的军事战略思 想。老子说: “古之用兵者有言: “吾不敢为主而为客, 不敢进寸而退尺。”(《道德经·69 章》) 具体地说就是不做“有为”的进犯者, 而采取守势; 不敢前进一步, 而宁可后退一尺。老子认 为: “舍其后, 且先, 则必死矣。夫慈, 以战则胜, 以守则固。” (《道德经・67 章》) 逞强 好胜必败无疑, 心怀慈爱, 坚守或出战都能克敌制胜。所以, 仁爱之心才是战争与和平的法 宝。

其次, “祸莫大于轻敌, 轻敌几丧吾宝。”(《道德经·69 章》) 即兵之大忌在麻痹轻敌。 老子说: “我有三宝持而保之: 一曰慈, 二曰俭, 三曰不敢为天下先。”(《道德经.69 章》) 用老子的军事哲学思想来理解“三宝”, 其意是说在战略战术上要是麻痹轻敌就是死路一条。 尤其是第三宝“不敢为天下先”，是让军队处在有利的位

置, 以静制动, 以不变应万变, 以无为对有为的制胜法宝。老子进一步解释说: “慈故能勇, 俭故能广, 不敢为天下先故能成器长。”那么骄傲、麻痹、自大、轻慢, 就不会勇、广、成器 长, 就会向不利的方面发展转化, 就会失败。朝鲜战争时期盟军最高统帅麦克阿瑟, 在 1950 年 11 月面对兵力部署不清的中朝军队, 武断认为中国不会大规模出兵, 建议对中国东北地区 大轰炸，杜鲁门政府有恐触发第三次世界大战，因此把战线划在鸭绿江以南。11月 24 日， 麦克阿瑟狂妄地宣称让美国士兵“回家过圣诞节”。结果在 12 月份被中国军队打得大败, 向南 撤出了三八线。这就是骄傲自大、麻痹轻慢的下场,

老子的“慈为万物慈, 俭为万世俭, 不敢为天下先, 也有为天下谋太平的思想旨趣。只要 人人都能够谦让卑下, 从不逞强或争霸, 人人、家家、国国和天下不就处于和平安泰之中了 吗? ”3如果都好勇斗狠, 利益之争各不相让, 天下真就是永无宁日了。资源有限争夺无限, 国与国之间真要搁置争端学学“无为”。阿富汗战争、伊拉克战争和利比亚战争硝烟未散, “伊 斯兰国”又开始猖狂作乱, 加之阿富汗塔利班卷土重来, 使得大批难民不断外涌, 形成“二战” 以来规模最大的难民潮。这是悖逆老子“三宝”的。据联合国难民署发布的数据显示，截止到 2015 年底, 全球共有约 6000 万流离失所者, ${ }^{4}$ 其中, 逃离本国、前往他国谋生的难民数量约 2000 万人，估计已有超过 46 万难民和非法移民渡过地中海前往欧洲, 其中大约 3840 人 死在途中。5

看到那些处于动荡或战乱之中的国家和流离失所的难民，我们反对战争，不就是慈吗? 美国每年在中东消耗的军费就有六千亿美金，没有战争这些钱不就节俭了吗？

第三, 哀兵必胜与人民战争的军事思想。老子认为两军实力相当的时候, 悲痛的一方可 以获得胜利。“故抗兵相若, 哀者胜矣。”( 《道德经· 42 章》) 张松如认为: “今人或谓老子 以退为进的方针, 在军事方面, 则表现为以守为主, 以守取胜的主张。这条总的作战原则是 不对的, 但老子提出的不可轻敌和双方兵力差不多相等的条件下, 悲愤的一方将获胜等见解, 还有它合理的地方。”公元前 207 年项羽率领 6 万楚军会同后期参战的各诸侯义军，同秦将 章邯、王离所率 40 万秦军主力在巨鹿决战, 项羽叔父项梁战死。这年底, 项羽怀着必死的决 心率军渡河, 破釜沉舟, 断绝秦军粮道, 一鼓作气, 以一当十, 经过九次激烈战斗终于打退 章邯, 活捉了王离, 围困巨鹿的秦军被瓦解。这是老子“哀兵必胜”与孙子“置之死地而后生” 


\section{(《孙子·九地》) 的典型战例。}

老子说: “慈故能勇...... 夫慈, 以战则胜, 以守则固。天将救之, 以慈卫之。”(《道德 经- 67 章》）毛泽东在《论持久战》中提出的“兵民是胜利之本”就符合老子的人民战争的理 念，这对达到后发制人的持久战的战略目的，争取战争的最后胜利具有决定作用和积极意义。 统治者如果平时爱护老百姓，外敌来犯他们会积极参与战争，统治者才能战必胜守则固。天 意要援助的是正义之战, 就会用慈爱来保护。毛泽东的官兵一致、不拿群众一针一线就是老 子的“慈”。在老子看来, 人民战争是决定军事进攻或防御成败的决定因素, 胜利的根本在于“兵 民”的团结一致对外抗敌。

\section{2“无为”的治国方案与“以奇用兵”的战略思想}

老子说: “以正治国，以奇用兵，以无事取天下。吾何以知其然哉？以此：天下多忌讳， 而民弥贫; 人多利器, 国家滋昏; 人多伎巧, 奇物滋起; 法令滋彰, 盗贼多有。故圣人云: ‘我 无为，而民自化；我好静，而民自正；我无事，而民自富；我无欲，而民自朴。”（《道德 经·57 章》）这是借“圣人”之言，阐释的“无为”思想，就是说应以“无事取天下”。老子在百姓 贫困、国家昏暗、物欲横流、盗贼泛滥的混乱时局面前，提出了“无为”、“好静”、“无事”、“无 欲”的“以正治国”的治国方案和“以奇用兵”的军事策略。

“以奇用兵”, 是说用兵是一种“兵者诡道也”的奇妙和诡诈行为, 就是不按惯常思维行事, 要想象奇特创新创意的超常思维, 才会出奇制胜。治国要正, “政者, 正也, 子帅以正孰敢不 正？”（《论语·颜渊》）做官要正，不正就无法治国；用兵要奇，用兵讲术，“正”就无法用 兵, 变化莫测不按常理出牌, 才符合战争不正常的规律, 是国家秩序混乱下采取的一种非常 手段。在战争不可避免的情形下，老子提出了“以奇用兵”的战略思想，具体表现为“不为天下 先”的后发制人的战略思想。

“不为天下先”后发制人的战略手段，在政治上占理，不首先挑起战争，在战略上顺应了 民意赢得了民心，这是人民战争最重要的因素。老子强调“以道佐人主者，不以兵强于天下”， 治理国家靠的是政策和策略, 而不是不义之战的巧取豪夺。老子反对战争, 并不是刀枪入库, 他把战争作为万不得已的终极选择, “不得已而用之”是自卫战争的手段。又告诫自卫战争的 发动者, 即使胜利了, 也要“恬淡为上, 胜而不美”, 所以, 老子的战争思想包含了反战和自 卫战争的悲天悯人的复杂心态。

实行“不为天下先”后发制人的战略手段，这在战术上是一种以静制动以不变应万变的军 事观察准备阶段。对于知彼, 熟悉对方的兵力部署、军事设施、侵略意图等; 知己, 军备情 况、民众安全、国家财产保护，还有兵力分配、各兵种协同作战、战略方案制定等等，都要 有个科学、妥善、安全的准备过程。知已知彼才能百战不殆, 不打无准备之仗就是这个道理。

\section{3.反对工艺技巧，主张“不以兵强天下”}

老子生活在春秋晚期正是诸侯争霸战乱不断民生调敝时期，“天下有道，却走马以粪。 天下无道, 戎马生于郊。” (《道德经·46 章》) 和谐社会太平盛世春和景明人们赶着马车送 粪种地; 战火袭来连年兵荒马乱, 连临产的母马也要上战场把马驹生在旷野荒郊。他不忍目 睹这兵荒马乱的战乱景象, 于是辞掉官职西出函谷浪迹天涯, 就说明了他对战争和乱世的极 大厌恶，这样看来他反对发明创造，就有了合理的因素。

\section{1 反对工艺技巧}

老子在《道德经》第 57 章中明确提出了反对工艺技巧，反对科技发明的主张，认为这是 引发社会混乱和战争的根源。胡寄窗说: “老子把工艺技巧认定为社会祸乱的原因, 他们要求 
废除工艺技巧，甚至认为盗贼之产生也是由于工艺技巧的关系。”7不能不说老子犯了极左错 误, 其实是科技与人文的冲突。科技进步加速了生产力的发展, 社会生活发生了重大变化, 同时科技尤其是军工科技也给生活带来了灾难。核电的科技革命给人类带来了新能源，爆炸 给人类带来了灾难, 如切尔诺贝利核电站爆炸。科技发展促进了社会的进步, 但对环境与生 态的破坏也是有目共睹的。美国在 1945 年 8 月 6 日和 9 日向日本广岛、长崎投放原子弹，轰 炸造成的伤害遗留至今, 辐射后遗症造成的癌症、白血病和皮肤灼伤等的伤痛依然折磨着幸 存者。科马克・麦卡锡在他的小说《路》描绘了这种景象: “城市几乎完全被烧毁, 自然界中 的树木花草也被烧毁，没有了生命的迹象，世间的一切皆笼罩在厚厚的灰尘之中; 天下万物 失去了支撑, 在灰蒙蒙而又阴森森的空气里无所无靠。核爆十年之后, 地球仍是废墟一片, 寰宇间阴暗冷凄。白天灰暗如黑夜, 夜晚冰冷不堪; 周围的森林是幽暗的, 大地依然是荒凉、 静寂而邪恶。”8老子反对战争给社会带来的危害, 尤其反对战争对生命的摧残, 这是爱人和 对生命的尊重, “老子把人在宇宙中的地位提升到前所未有的高度, 可谓最早的“以人为本”的 思想基石。”

\section{2“不以兵强天下”解决国与国的利益之争}

老子说: “君子居则贵左, 用兵则贵右。兵者, 不祥之器, 非君子之器, 不得已而用之, 恬淡为上。…吉事尚左, 凶事尚右。偏将军居左, 上将军居右, 言以丧礼处之。”(《道德 经·31 章》) “左阳道, 朝祀之事; 右阴道, 丧戎之事。”(《毛传》) 按中国夏商周传统礼俗, 朝官尊左, 左主阳, 代表男性、光明、喜庆、吉祥, 因此朝拜祭祀等居左为尊; 右主阴, 代 表女性、黑暗、丧葬、战争等, 所以燕饮、凶事、兵事居右为尊。另外左吉右凶也是预测事 情好坏的一种方法, 比如到今天民间还有左眼跳财右眼跳祸的说法, 抱拳礼以左抱右, 谓之 抱凶。这也是符合夏商周礼的，今天民间仍沿袭男左女右的区分。这说明中国自古民俗礼仪 是把战争当做“不祥之器”来看待的, 因为战争是死人的丧事, 所以属阴、凶事、祸事, 即使 胜利也要“以丧礼处之”。

人类社会进入到数字化时代，远隔千山万水手指轻轻一按一座城市瞬间灰飞烟灭，就是 毁灭我们人类共同的家园地球也是顷刻之间的事。老子的“道”是探讨自然界的发展规律，提 出用顺应自然的“无为”思想来治理天下是符合“道”的，劝告君王不能用战争手段强取豪夺， 才是人类和平共处的根本。“洛克认为人类的自然状态是一种自由平等、和平和睦的状态。”10 “不以兵强天下”解决国与国的利益之争, 老子说: “以道佐人主者, 不以兵强天下。其事好还。 师之所处, 荆棘生焉。大军之后, 必有凶年。” (《道德经》30 章) 二战中德、意、日三元 凶希特勒、墨索里尼、东条英机, 图谋以战争逞强天下称霸天下，侵略他国“师之所处，荆棘 生焉”，生灵涂炭，民生调敉; 自己的国家也落了个一片废墟，二战中德国死亡近千万，日本 死亡六百多万。正如老子所说: “物壮则老, 是谓不道, 不道早已。”这是物极必反的自然规 律，违背这个规律，害了别国，也害了自己。习近平以和平、发展、治理三大赤字指明人类 面临的严峻挑战, 以“人类命运共同体”理念引领时代方向。11这是符合老子战争辩证法哲学思 想的英明论断，新世纪世界各国必须拉起手来关注人类的共同命运，才会避免战争享受和平。

\section{4. 国际之间修“水道”与“水德”行处下之道谦下之德}

这是说的国家素质问题，其实是决策层的问题。每个国家都谋求修“水道”与“水德”行处 下之道，那么整个国家国民素质就提高了，决策层的素质就会更加提高了，这样，每个国家 都能安静下来, 像水一样处下不争, 战争是可以避免的。 


\section{1 “水道” 是处下之道, 在对待外强入侵时坚守正义赢得国际支持}

道是万物的本源, 是本来就该如此的样子, 也是自然之道, 生命之道, 科学之道。当“道” 以万物本源的身份出现时, 与水没有什么关系, 是老子在发现这个“道”体时, 要寻找一个客 观实在物作参照作比喻来加以解说。在寻找中老子是痛苦的, 这正如孕育新生命的诞生, 老 子对“道”是这样描绘的: “是谓无状之状, 是无物之象, 是谓惚恍。迎之不见其首, 随之不见 其后。”12水中蕴藏着丰富的资源和神秘的景观, 所以, “其精甚真, 其中有信。”(《道德经·21 章》）以水与道作比是老子的重大发现, “上善若水”, “水”不但形状与“道”相像, 而且品质 依然相像。“道冲而用之, 或不盈。渊兮似万物之宗。”(《道德经·4 章》) “道”像个容器因 为“空”才给人用不完的使用余地，“渊兮似万物之宗”，江河湖海的渊深广大，是孕育生灵万 物的摇篮。

老子是这样阐释 “水道”的: “天下莫柔弱于水, 而攻坚强者莫之能胜, 以其无以易之。” (《道德经·78 章》) “天下之至柔, 驰骋天下之至坚。”(《道德经·43 章》) “滴水石穿”, 水性至柔, 却无坚不摧; 柔能克刚, 气势凶猛, 有洪水猛兽之喻。“柔弱”属阴性, 比如孩童、 女性、水等，其中包含有坚韧不拔的性格。老子的“水道”是他“无为”思想的形象化阐释，把 它应用到军事战略上, 就是“不得已而用之”, 后发制人, 方能“弱之胜强, 柔之胜刚”, 因为 胜利在正义一方, 骄兵必败, 哀兵必胜。1948 年 5 月 16 日, 也就是以色列建国的第二天早 晨, 阿拉伯国家联盟的 4 万军队进犯以色列。战争一开始, 以色列总兵力只有 3.4 万, 飞机 33 架, 仓促应战节节败退。以色列总理急电驻联合国代表要他游说联合国协调停火调整军备。 6 月 11 日, 阿以双方同意停火四周。就在这四周时间里, 以色列政府建起了一支正规的以色 列国防军, 又得到了来自天下各地的犹太人捐赠的新型轻重武器。当 7 月 9 日阿拉伯联军再 次进攻之时, 以色列军队牢牢抓住稍纵即逝的战机, 针对联军主力埃及军队溃败, 联军即溃 的弱点, 一鼓作气连败埃军, 埃军败退, 联军节节败退。第一次中东战争结束, 以色列完胜。 ${ }^{13}$ 以色列“不得已而为之”打了一场以少胜多, 以有义对无义的自卫战争, 充分证明了老子“柔 弱胜刚强”的军事论断。

\section{2 水德就是谦下之德, 在对待国际事务上就是要谦让尊重、处下不争}

老子说: “故贵以贱为本, 高以下为基。是以王侯自称孤、寡、不毂。”(《道德经·39 章》) 这是“柔弱胜刚强”哲学思想的延伸到王者之道, “贵贱”、“高下”两对矛盾相互依存, 王侯因 此低调自贬。就如王者, 高高在上不需要荣誉, 没有贪欲, 王侯才会活得玉石般硬气, 才会 王者天下。老子继续阐述他的哲学思想: “大邦者下流, 天下之牝, 天下之交也。牝常以静胜 牡, 以静为下。故大邦以下小邦, 则取小邦; 小邦以下大邦, 则取大邦。”(《道德经·61 章》) 这是“柔弱胜刚强”哲学思想延伸到大小国和平共处的外交关系, 拿水的上下流与国的大小作 比, 这上下大小的矛盾, 下和小又好比雌柔, “柔弱胜刚强”。大国对小国谦下忍让, 小国就 会信任和依赖大国, 反之, 小国对大国尊敬礼让, 大国就会包容小国。懂得这个道理, 还要 把握自己的分寸, “大邦不过欲兼畜人，小邦不过欲入事人。夫两者各得所欲，大者宜为下。”

(《道德经.61 章》) 就是说大小国都要懂得克制, 大国不要过分想凌弱小国, 小国不要过分 顺从大国，假如都克制不住怎么办？大国应该谦忍为上，就是大国要有胸怀。在《道德经》 第 66 章, 老子提出了“海纳百川”无与伦比的包容气度: “江海所以能为百谷王者, 以善下之, 故能为百谷王。”这一章, 老子再次强调了因水居下, 而百川归之。而引出君王欲在民上, 必 法江海谦虚、“先天下人之忧而忧, 后天下人之乐而乐。”这样, 天下就没人能与他争了。老 子在告诉人们: 治人, 需治心, 以人格魅力征服人, 比用法制约束人更有效, 对于我们教育 工作者来说, 也许一次谈话, 一个鼓励的眼神, 一次游戏, 会比一次训诫管用得多。

“处下”“谦下” 的水德是处理国与国之间关系的一个重要原则。“2 0113 年，习近平主席访 
问拉美。不论是只有几万人口的小国，还是有 1 亿多人口的大国，习主席都同样以诚相待，生动 诠释了中国坚持大小国家一律平等的外交原则。”14 “习式外交”符合老子提出的大小国家都要具备 水德的修养，居上处下互相尊重，才会避免战争实现天下和平的“水”道。

国与国之间形式上有大小，国格上无大小，不能以大欺小恃强凌弱，也不能因为小因为 穷就摆出一副穷凶极恶的样子, 争强好夺, 从而实现各国和平共处的和谐发展格局。在南海 问题上美国就是好事者, 隔了个太平洋手就伸过来了, 插手南海搅局, 目的就是要充当天下 老大, 从中获利。2016 年 10 月 21 日, 美国以兵强天下军舰未经中方批准擅自进入南海, 闯 入西沙群岛的中建岛和伍迪群岛 12 海里, 不但严重违反国际法, 更是蓄意挑衅。中国海军舰 机在现场第一时间采取了应对行动，海军“广州”号导弹驱逐舰和“洛阳”号导弹护卫舰，对美 舰进行识别查证, 并予以警告驱离, 中国外交部和国防部也进行强烈谴责。国与国之间都要 主动谦下, 互相尊重, 不能以老大自居, 挑拨菲律宾、越南这些小国挑畔中国, 最后毕竟会 搬起石头砸自己的脚。

水德就是柔德弱德, 在《道德经》第 78 章, 老子强调了水的柔弱: “天下柔弱, 莫过于 水”。紧接着, 又盛赞水的坚强: “而攻坚强者, 莫知能胜。”在此基础上, 老子赋予了天下君 王承担国家耻辱，承受国家灾祸的责任: “受国之垢, 是谓社稷主; 受国不祥, 是为天下王。” 吃得苦中苦, 方为人上人, 说的就是这个道理。

柔弱如水, 比如贞儿, 比如女性。智者如水, 水给人的启示是否还可以理解为: “心如止 水”, 随时以心灵的宁静, 来完成个人的积累与修为, 最终无声胜有声。

\section{3“上善若水”是老子水德的哲学总纲, 是谋求和平必须坚持的外交准则。}

1.水有“处下” “不争”的崇高品德, 体现了道的特征。“上善若水, 水利万物而不争, 处众 人之所恶，故几于道。”(《道德经· 8 章》) 恍惚无形的水的形状与品质最接近老子之“道”, 水, 随物赋形, 俯首操劳甘于奉献, 这是人类高贵品质的象征。“万物恃之以生而不辞, 功成 而不居, 衣养万物而不为主。” (《道德经·34 章》) 水具有滋养万物生命而甘居卑下的美德, “到江送客棹, 出岳润民田”, 这种人格化的美德正是“道”的特征: “万物作而弗始, 生而弗有, 为而弗恃, 功成而弗居。” ( 《道德经·2 章》) 老子以水德的“不争”精神, 提醒国与国外交 做到“为而不争”。这种“不争”, 并不是认输服软, 也不是闭关锁国或固步自封; 他的“不争”, 是一种积极的“恬淡为上”态度。他提出国与国外交要努力去“为”, “为”是礼让包容协调关系 互通有无，要像“利万物”的水一样，看着别国好，自己开怀笑，天下和平共荣是“为”的方向。

2.“处下”是“不争”的一种重要表现形式。老子说: “道之在天下, 犹川谷之与江海。”(《道 德经·32 章》) 老子从水德提炼出道的特征, 进一步以水比喻阐释“道”。就是说有“道”的奉献, 才有天下的归依, 正如千条河川归江海一样。老子又把道理提升到治国, 说: “治大国若居下 流，天下之交，天下之牝。”(《道德经·61 章》) 治理国家君主要有守住阴柔, 甘居人下勇 于奉献的精神, 这正如“江海所以能为百谷王者, 以其善下之, 故能为百谷王。”统治者也是 这样, “是以圣人欲上民, 必以言下之, 欲先民, 必以身后之, ......是以天下乐推而不厌。”

(《道德经·66 章》) 统治者要处理好“上下”“先后”的矛盾, 谦虚处下, 把自己国家的利益置 于别的国家利益之后, “先天下之忧而忧, 后天下之乐而乐”。老子从水的处下而成大江大海 的这一客观现象, 提醒我们在国际交往中要以“处下”的态度, 具备海纳百川的胸怀, 才能避 免战争赢得和平。

大国科技发达资源丰富军备强大容易产生“以兵强天下”的骄横作风，容易犯穷兵黩武的 过失。美国以反恐为名推翻萨达姆政权和发动利比亚战争, 就是要维护自己的天下霸主地位, 再就是石油利益。大国强加小国的利益之争, 是对小国的欺凌, 势必会遭到武力的反抗, 从 而引发战争。老子的水德对处理国与国之间关系是十分实用的哲学思想, 深谙此道对处理今 
天战争与和平的关系，仍然具有十分重要的现实意义。战争一旦开启地球就面临毁灭，“春秋 无义战”, 或许多读读老子, 就可以参悟透“道”的“惚兮恍兮”, 不争谦下, 这样天下就会和谐。

\section{References}

[1] "Harmony" leads the way of China's peaceful development -- Interpretation of President Xi Jinping's speech at the 60th anniversary commemoration of the Chinese people's Association $\begin{array}{llll}\text { for friendship with foreign } & \text { countries. }\end{array}$ http://politics.people.com.cn/n/2014/0517/c1001-25030134.html

[2] Zhang Zhaozhong: China does not take the initiative to provoke war, but to prepare for war.[EB/OL].http://mil.sohu.com/20120913/n353022188.shtml

[3] Liu Yang. Re understanding of the three treasures of Tao Te Ching [N]. China national newspaper,2012-04-17.

[4] Who is the initiator of the largest refugee tide after World War II [EB/OL]. http://www.vccoo.com

[5] Look at economic development with the concept of "fate community" [EB/OL].http://bbs.workercn.

[6] Zhang Songru. Lao Tzu reads [M]. Changchun: Jilin people's publishing house. 1985-05, 380.

[7] $\mathrm{Hu}$ Hui window. History of Chinese economic thought (Part I) [M]. Shanghai: Shanghai people's publishing house.1981 - 01, 211.

[8] Cormac McCarthy. the Road[M].Copyright M-71， Ltd. Library Genesis， 2006. Web. Mon.9 Oct.2015.

[9] Liu Tinghua's Laozi's war view and military strategy (Part one) -- a study of the history of [J].'s military ideology without "strengthening the world by force" and building a harmonious world.2009(3)44-46

[10]Richard T.Schaefer.Sociology[M].McGraw-Hill Education - Europe, 2011-10-01

[11]Xin Shiping: where does the charm of "learning diplomacy" come from. [EB/OL]. http://news.xinhuanet.com/politics/2017-08/31/c 1121580204.htm

[12]Cheung, Leo K.C..The metaphysics and unnamability of the dao in the Daodejing and Wittgenstein[J].Philosophy East and West.April,2017,Vol.67 Issue 2,p352,28 p

[13]Muhammad Youssef Suwaed.The Bedouins in the Galilee in the War of Independence of Israel 1948- 1950[J].Middle Eastern Studies, 2017, Vol.53 (2), pp.297-313.

[14]Xin Shiping: where does the charm of "learning diplomacy" come from .[EB/OL]. http://news.xinhuanet.com/politics/2017-08/31/c_1121580204.htm 